\title{
Xanthogranulomatous pyelonephritis
}

\section{A comparison of the disease in the cat and man with special reference to the origin of the fat}

\author{
G. B. D. SCOTT AND P. J. QUIGLEY
}

From the Department of Morbid Anatomy, The Royal Free Hospital, and the Blue Cross Hospital for Animals, Pimlico, London

SYNOPSIS The origin of the intracellular fat in human xanthogranulomatous pyelonephritis has been the centre of some discussion in the past. A report of a case in a domestic cat is of interest as normal feline renal epithelium is rich in stainable fat. A comparison of the human and feline varieties of xanthogranulomatous pyelonephritis reveals certain fundamental differences between the two and reinforces the view that the fat concerned in the human disease does not originate in the renal epithelium.

In man the characteristic feature of the xanthogranulomatous variety of chronic pyelonephritis is the presence of large numbers of macrophages laden with fine intracytoplasmic fat. The condition, sometimes called 'foam-cell granuloma', is associated particularly with urinary obstruction and suppuration (Heptinstall, 1966). The chronic inflammatory process is proliferative, and occasionally cases are mistaken for neoplasm (Avnet, Roberts, and Goldberg, 1963) or tuberculosis (Barrie, 1949; Mack and Mador, 1952).

Its reported incidence varies, Hooper, Kempson, and Schlegel (1962) collecting 15 cases over three years and Friedenberg and Spjut (1963) 12 cases over 10 years, while Ghosh (1955) found only three examples amongst 222 consecutive kidneys removed surgically for a variety of inflammatory conditions. On the other hand, Castleman (Leadbetter et al, 1962) asserts that fat-laden macrophages occur so commonly in longstanding renal abscesses that the specific term 'foam-cell granuloma' is not justified.

The exact origin of the fat is still undetermined. Visible fat has not been described as occuring in the renal epithelium in cases of chronic pyelonephritis, and therefore a renal origin has tended to be discarded in favour of an origin in the polymorphs present in the inflammatory tissue (Heptinstall, 1966).

Since feline renal epithelium is normally laden with visible fat, the finding in a domestic cat of a chronic renal disease closely resembling human xanthoReceived for publication 9 November 1971. granulomatous pyelonephritis allowed of a comparison of the disease in the two species with particular reference to the origin of the fat in the human variety.

\section{Case Report}

A neutered male cat, whose estimated aged was 8 years or more, had developed gingival ulceration. No other abnormal signs could be found and investigation showed a haemoglobin of $12.0 \mathrm{~g} \%$ (normal $8 \cdot 0-14.0 \mathrm{~g} \%$ ) and a total of 7450 white blood cells per cmm (normal 8000-25000 per c $\mathrm{mm})$, predominantly polymorphonuclear leucocytes. The urine had a specific gravity of 1056 (normal 1020-1 045), with heavy albuminuria. The blood urea was $42.8 \mathrm{mg} \%$ (normal $26 \cdot 0-80 \cdot 0 \mathrm{mg} \%$ ).

The gingival ulceration responded to steroids but recurred once treatment was stopped. Although it responded again to treatment such relapses became increasingly frequent and the animal was destroyed.

At necropsy, apart from the gingival ulceration, the macroscopic changes were confined to the kidneys which were of normal size and showed the extreme cortical pallor characteristic of the species. Irregular shallow cortical scars were present on both surfaces of the right kidney (Fig. 1) but the organ seemed otherwise normal. Three slightly raised white areas, reminiscent of lymphosarcomatous infiltration, were present in the cortex of the left kidney, obliterating the normally readily visible cortico-medullary junction. The remainder of the urinary tract was passed as normal. 

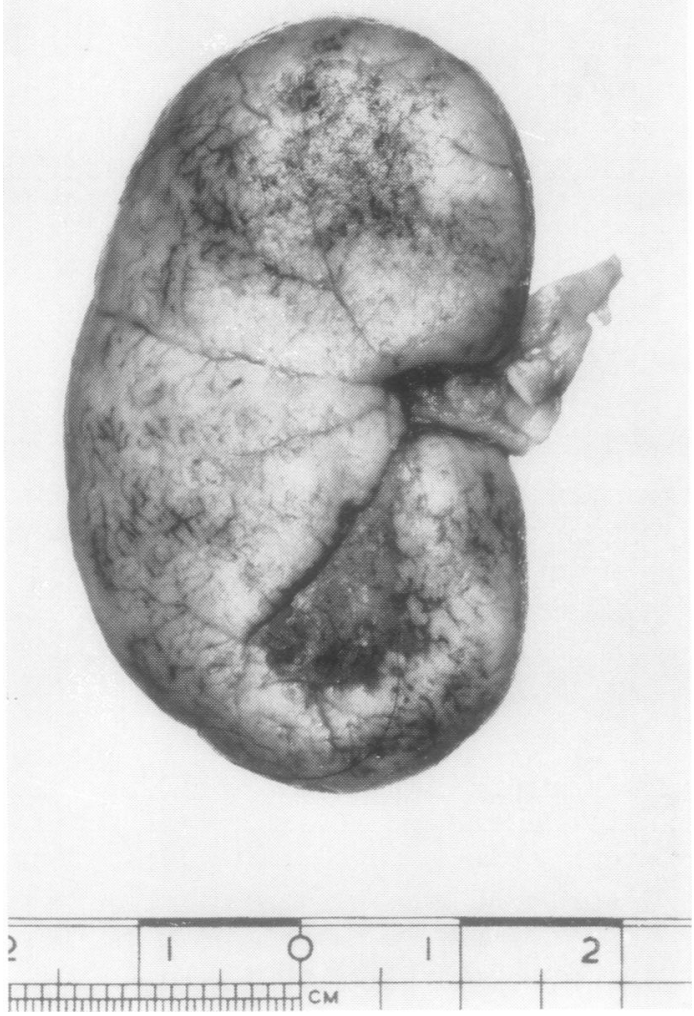

Fig. I Right kidney with shallow cortical scar ?.

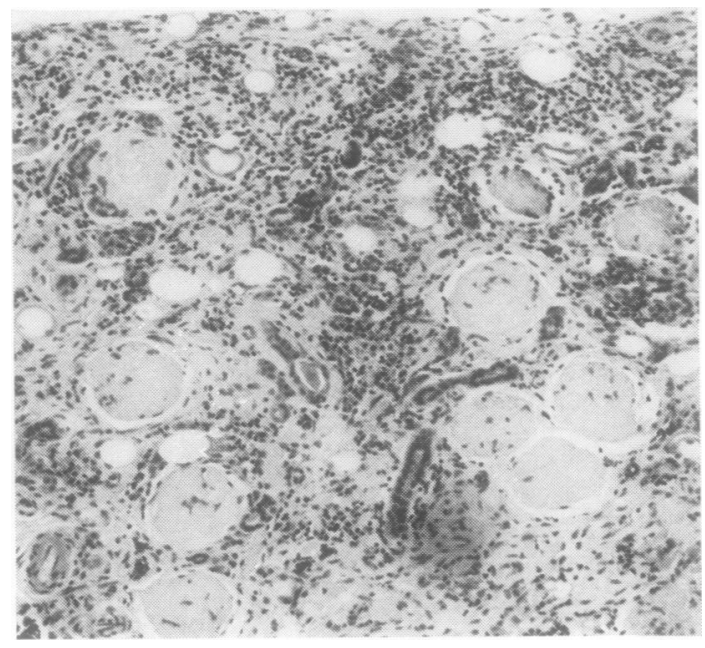

Fig. 2 Shallow renal scar in right kidney showing loss of renal tubules and scarring of glomeruli. Haematoxylin and cosin 120 .
Microscopically the tubular cells of the normal $\stackrel{\stackrel{0}{\overrightarrow{0}}}{\text { ( }}$

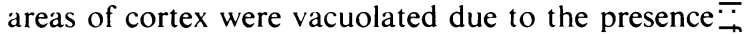
of intracellular fat, staining strongly with Oil Red $\mathrm{O} \overrightarrow{\overrightarrow{\vec{s}}}$ but showing very little birefringence. The shallow $\overrightarrow{0}$ cortical scars in the right kidney (Fig. 1) showed듬 massive loss of renal tubules and their replacement $\overline{\overline{\bar{\omega}}}$. by fibrous tissue containing small clusters of lymph- $\widehat{\Phi}_{0}$ oid cells, while the glomeruli, all fibrosed ando hyalinized, were crowded together (Fig. 2). A small ${ }^{\text {( }}$

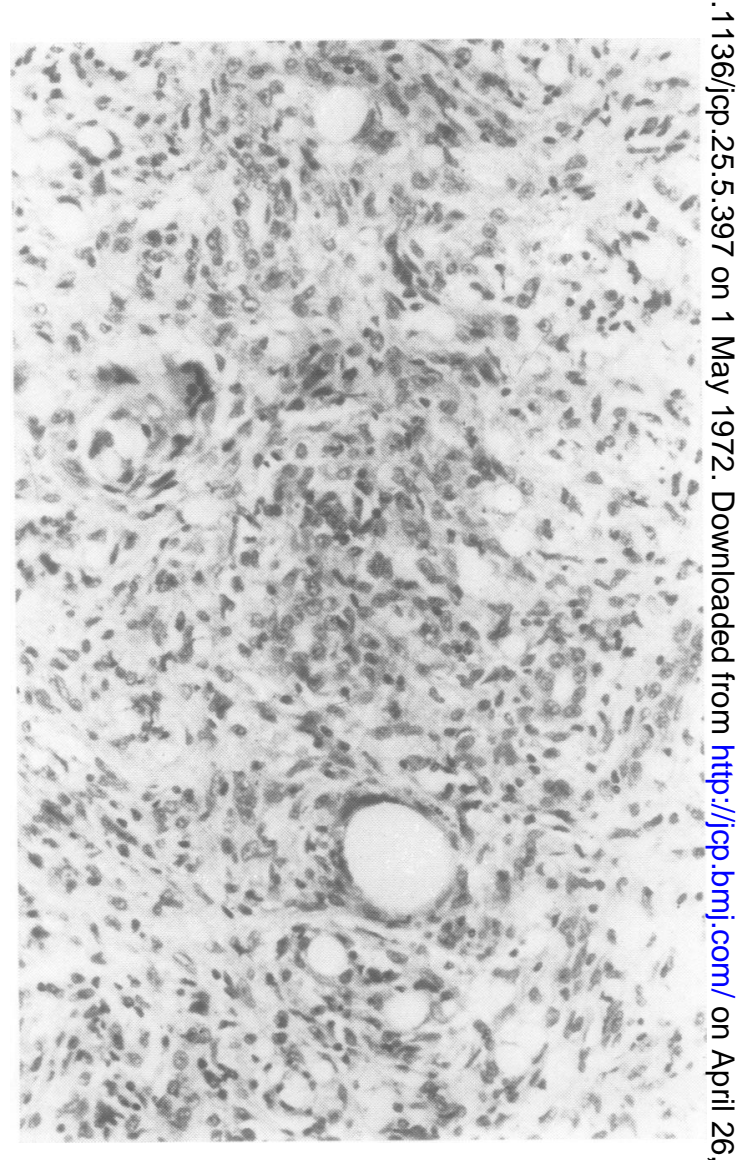

Fig. 3 White area in left kidney showing fibroblasts and mononuclear cells. Some cells have foamy cytoplasm, while others contain discrete droplets of fat. Haematoxylin anc $\omega^{\omega}$ cosin 189.

quantity of fine fat, not obviously intracellulare could be demonstrated with Oil Red $O$ but no bire- fringence could be seen under polarized light.

In the white expanded areas in the left kidney the renal tissue had been largely replaced by numerousD fibroblasts (Fig. 3) and collections of lymphoid and mononuclear cells, many of the latter having foamy granular cytoplasm. Small round or elongated cyst 
containing fat, which stained with Oil Red $\mathrm{O}$, were scattered throughout these areas, the fat being surrounded often by syncytial formations. Whether the latter were of epithelial or inflammatory origin could not be determined. Such glomeruli that remained were either infiltrated with chronic inflammatory cells or showed progressive fibrosis.

These pale areas also contained much finely divided fat, also staining with Oil Red $O$. While a proportion of this material could be identified as lying in the cytoplasm of mononuclear cells, often as quite large discrete droplets (Fig. 3), the exact site of much of it could not be determined and it might well have been lying free amongst the fibroblasts and inflammatory cells. No birefringence could be elicited.

\section{Human Xanthogranulomatous Pyelonephritis}

A search of the files of the department of Morbid

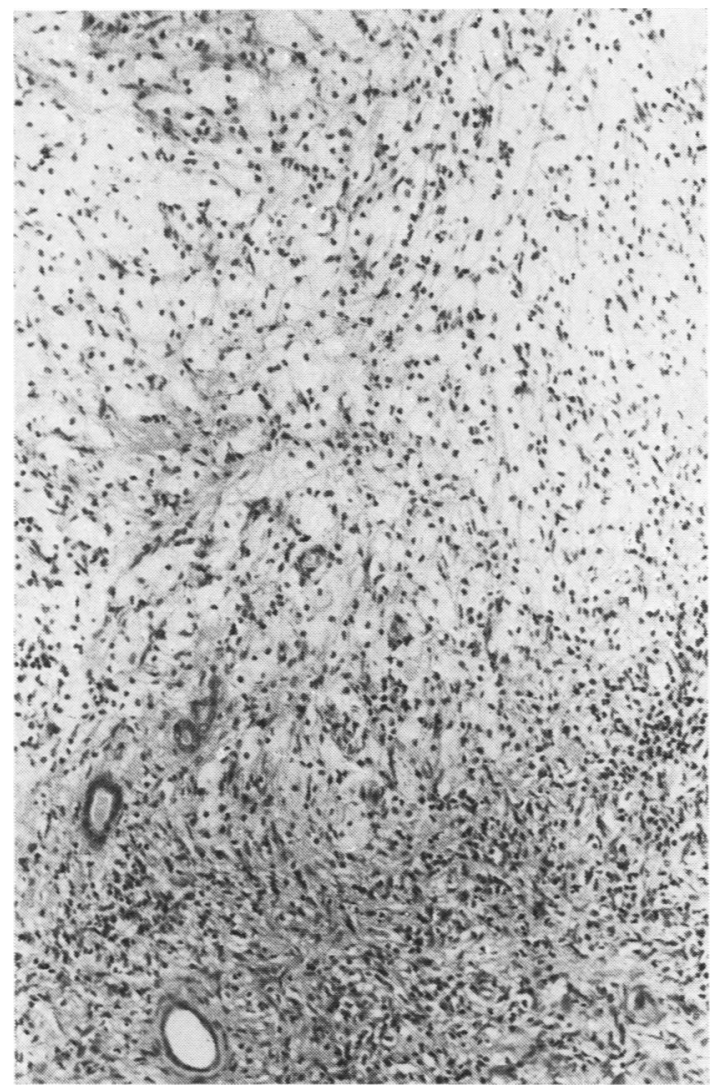

Fig. 4 Human case (Royal Free Hospital 176/66) showing large numbers of fat-laden cells with clear cytoplasm. Remnants of collecting tubules are present. Haematoxylin and eosin $\times 120$.
Anatomy at the Royal Free Hospital produced two examples of the human disease from the last 10 years. Both cases were associated with urinary obstruction and consequent destruction of renal parenchyma. Both human cases contained many more fat-laden 'foam cells' than did the feline one and even when occurring singly or in small groups they could be more easily identified amidst the chronic inflammatory and fibrous tissue as their cytoplasm was clear compared with that of their feline counterparts (Fig. 4). Giant cells of varying size were present in both human cases but were absent in the cat.

Unfortunately no unembedded tissue was available and investigation of the fat could not be undertaken.

\section{Discussion}

The shallow depressed cortical scars in the right kidney (Figs. 1 and 2) were more reminiscent of the human 'arteriosclerotic' kidney than of classical chronic pyelonephritis. On the other hand, the projecting homogeneous white areas in the left kidney, shown by microscopy to be proliferative chronic inflammatory lesions, rich in fat (Fig. 3), resembled human xanthogranulomatous pyelonephritis, the more so since, in the cat, renal scars, whatever their cause, are usually depressed below the cortical surface (Lucke, 1965).

Although a search of the literature failed to reveal any reports of classical xanthogranulomatous or 'tumefactive' pyelonephritis, in the cat or indeed in any other animal, the case reported here undoubtedly resembles those of chronic renal disease described in the cat by Lucke (1965) in which, following massive 'accelerated tubular disruption', intraepithelial fat is released into the interstitial tissues exciting an exuberant fibrous tissue reaction.

The interest of this single case centres around a comparative study of the nature of the fat in human and feline xanthogranulomatous pyelonephritis and consequently the origin of the fat in the human variety.

The majority of published descriptions of the condition in human cases make little or no reference to the fat present although occasional cholesterol clefts have been reported (Hooper et al, 1962). However, Schlagenhaufer (1916) and Barrie (1948) refer to macrophages containing doubly refractile fat and examination of a recent case of which unembedded material was available (Dr R. C. B. Pugh) provided abundant confirmation.

Certain obvious differences between the feline and human varieties of the disease emerge. First the foam cells differ, both in number and in appearance. They are obviously more numerous in the human 
variety and their cytoplasm is clearer, resembling that of the cells of a classical hypernephroma. Secondly a high proportion of the fat in the human variety is doubly refractile, whilst no birefringence can be demonstrated in the feline variety even though the fat in both normal renal epithelium and in renal scars has a steroid component (Lobban, 1955; Lucke, 1965).

There can be no doubt that the fat in the granulomatous lesions in the cat is derived from the renal epithelium. On the other hand, the absence of visible and stainable intraepithelial fat in human examples of pyelonephritis has led to the exclusion of an epithelial origin for the fat in the xanthogranulomatous variety (Heptinstall, 1966). Furthermore examinations of frozen sections from the apparently normal kidneys of six patients dying from diseases not affecting the urinary tract, either directly or indirectly, revealed only very sparse droplets of stainable fat in occasional convoluted tubules and no birefringence under polarized light.

These fundamental differences between feline and human xanthogranulomatous pyelonephritis reinforce the contention that the fat in the latter variety is not derived from the renal epithelium.

A study of the reported cases of human xanthogranulomatous pyelonephritis certainly confirms the close association (Heptinstall, 1966) between the condition and ureteric obstruction and renal suppuration. This combination is notorious for producing changes in the calyces and pelvis together with destruction of renal tissue and involvement of the surrounding adipose tissue, thus raising the possibility that the latter site is the origin of the fat in human xanthogranulomatous pyelonephritis.

Our thanks are due to Dr R. C. B. Pugh of St Paul's Hospital, London, for allowing us access to the material of his case, to Dr V. M. Lucke of the $\stackrel{\mathbb{Q}}{\circ}$ Department of Pathology, the University of Bristol, for her opinion on the slides of the feline case, and to Professor E. Cotchin of the Department of Pathology, The Royal Veterinary College, London, for his advice and encouragement.

References

Avnet, N. L., Roberts, T. W. and Goldberg, H. R. (1963). Tumefactive of xanthogranulomatous pyelonephritis. Amer. J. Roentgenol., 90 , 89-96.

Barrie, H. J. (1949). Foam-cell granuloma in chronic pyelonephrosis simulating tuberculosis. Brit. J. Surg. 36, 316-319.

Friedenberg, M. J., and Spjut, H. J. (1963). Xanthogranulomatous pyelonephritis. Amer. J. Roentgenol., 90, 97-108.

Ghosh, H. (1955). Chronic pyelonephritis with xanthogranulomatous change. Amer. J. clin. Path., 25, 1043-1049.

Heptinstall, R. H. (1966). Pathology of the Kidney, ch. 15. Little Brown. Boston, Mass.

Hooper, R. G., Kempson, R. L., and Schlegel, J. U. (1962). Xanthogranulomatous pyelonephritis. J. Urol., 88, 585-593.

Leadbetter, G. W., Jr., et al (1962). Case Records of Massachusetts General Hospital case 9-1962 (Chronic abscess of right kidney). New Engl. J. Med., 266, 255-258.

Lobban, M. C. (1955). Some observations on the intracellular lipid in the kidney of the cat. J. Anat. (Lond.), 89, 92-99.

Lucke, V. M. (1965). Renal disease in the domestic cat. PhD Thesis, University of Bristol.

Mack, F. G., and Mador, M. L. (1952). Pyogenic (foam-cell) granuloma in a case of pyelonephritis. J. Urol., 67, 258-261.

Schlagenhaufer, F. (1916). Über eigentümliche Staphylomykosen der Nieren und des pararenalen Bindegewebes. Frankfurt. Z. Path. 19. 139-148. 